\title{
THE EFFECT OF SEROTONERGIC LESIONS IN THE MEDIAL PREFRONTAL CORTEX ON PSYCHOTOMIMETIC DRUG-INDUCED LOCOMOTOR HYPERACTIVITY AND PREPULSE INHIBITION IN RATS
}

\author{
Snezana Kusljic ${ }^{1,2}$ and Maarten van den Buuse ${ }^{2,3}$ \\ ${ }^{1}$ Department of Nursing, University of Melbourne, Carlton, Victoria, Australia \\ ${ }^{2}$ Behavioural Neuroscience Laboratory, Mental Health Research Institute, Parkville, Victoria, Australia \\ ${ }^{3}$ Department of Pharmacology, University of Melbourne, Carlton, Victoria, Australia
}

\begin{abstract}
:
While dysfunction of the prefrontal cortex has been repeatedly implicated in the pathophysiology of schizophrenia, the role of serotonin in this brain region in schizophrenia is unclear. We therefore examined the effects of local serotonin depletion in the medial prefrontal cortex on psychotomimetic drug-induced locomotor hyperactivity and prepulse inhibition, two animal models of aspects of schizophrenia. Pentobarbital-anaesthetised (60 mg/kg, i.p.) male SpragueDawley rats were stereotaxically micro-injected with 0.5 $\mu l$ of a $5 \mu \mathrm{g} / \mu \mathrm{l}$ solution of the serotonin neurotoxin 5,7-dihydroxytryptamine into the medial prefrontal cortex. Two weeks after the surgery, rats underwent behavioural testing. When compared to sham-operated controls, rats with me-
\end{abstract}

dial prefrontal cortical lesions did not show changes in either psychotomimetic drug-induced locomotor hyperactivity or prepulse inhibition. However, following the administration of the serotonin neurotoxin into the medial prefrontal cortex, the concentration of serotonin was reduced by $60 \%$. These results suggest that serotonin depletion in the medial prefrontal cortex does not lead to dysregulation of subcortical dopaminergic activity and does not cause aberrant responses to environmental stimuli.

Keywords: schizophrenia, serotonin, medial prefrontal cortex, prepulse inhibition

Running title: Serotonin, the medial prefrontal cortex and behaviour

\section{Abbreviations used:}

5,7-DHT- 5,7-dihydroxytryptamine 5-HT- 5-hydroxytryptamine, serotonin 5 - $\mathrm{HT}_{1-7, \mathrm{~A}-\mathrm{F}}-$ serotonin receptor subtypes ANOVA-analysis of variance $\mathrm{D}_{1-5}$ - dopamine receptors 1-5 DRN- dorsal raphe nucleus GABA- $\gamma$-aminobutyric acid HPLC- high pressure liquid chromatography i.p.- intraperitoneal MRN: median raphe nucleus mPFC- medial prefrontal cortex NMDA- N-methyl-D-aspartate PPI- prepulse inhibition PP- prepulse intensity PP8- prepulse of $8 d B$ s.c.- subcutaneous SEM- standard error of the mean VTA- ventral tegmental area

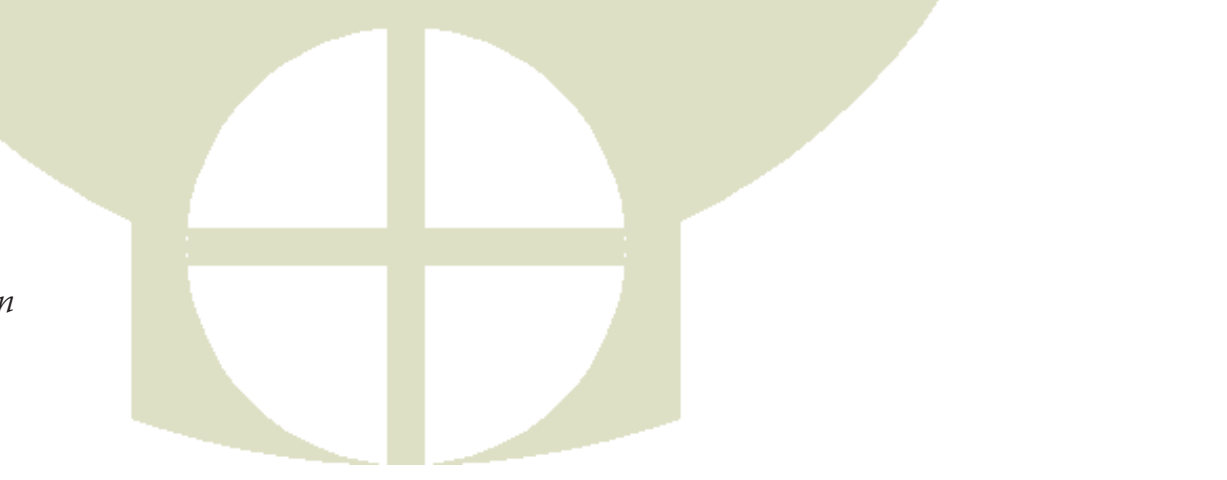




\section{INTRODUCTION}

Schizophrenia is a chronic and severe psychiatric disorder that generally occurs in late adolescence or early adulthood. Approximately $1 \%$ of the population worldwide is affected by schizophrenia, placing a heavy burden on society, both in terms of emotional suffering and economic loss [1]. Schizophrenia is the classic example of a disorder that always has psychosis as one of its features [2]. As psychotic episodes are extremely debilitating, management and treatment aim to reduce and eliminate these dramatic personality changes, consisting of irritability, confusion and paranoia associated with hallucinations and delusions. Antipsychotic drugs are used to treat nearly all forms of psychosis, including schizophrenia. It has been generally accepted that the mechanism by which antipsychotic drugs decrease hallucinations and delusions is mediated at least in part by dopamine $\mathrm{D}_{2}$ receptor blockade [3-5]. Moreover, atypical antipsychotic drugs, such as olanzapine, display a unique neuropharmacological profile; they minimise psychoses by interacting with a number of neurotransmitter and receptor systems through binding at multiple receptor sites. Olanzapine has a high affinity for serotonin $5 \mathrm{HT}_{2 \mathrm{~A}}$, dopamine, cholinergic, histamine and $\alpha 1$-adrenergic receptors [6]. However, the most important mechanisms underlying the clinical properties of atypical antipsychotic drugs appear to be mediated by interactions with the serotonin $5-\mathrm{HT}_{2 \mathrm{~A}}$ receptor subtype $[7,8]$.

Serotonin is one of the major neurotransmitters in the human brain and plays a central role in the regulation of a wide range of behaviours, such as mood, eating and the stress response [9-11]. The serotonergic projections arising from the brainstem raphe nuclei form the largest and most complex efferent system in the human brain [12, 13]. The axons of dorsal raphe nucleus (DRN) neurons contribute to the majority of the serotonergic innervation in the frontal cortex, ventral hippocampus and striatal regions $[14,15]$, while the axons of median raphe nucleus (MRN) serotonergic neurons are more abundant in the dorsal hippocampus and the cingulate cortex $[16,17]$. The hypothalamus, the substantia nigra and the nucleus accumbens receive serotonergic innervation from both nuclei $[18,19]$. This organisation of the serotonergic neuronal population suggests that serotonin is involved in the regulation of different functional systems, such as the motor, limbic and somatosensory systems [13]. Thus, it is not surprising that atypical antipsychotic medications target multiple brain serotonin receptor subtypes. As it is very difficult to assess alterations of serotonergic transmission in the pathophysiology of psychiatric disorders in the living human brain, animal models are needed.

Animal models of psychiatric disorders, including schizophrenia, rely on mimicking specific aspects or symptoms associated with the disease [20-22]. The two most widely used models are locomotor hyperactivity induced by psychotomimetic drugs and prepulse inhibition.
Psychotomimetic drugs, such as amphetamine and phencyclidine, can induce abnormal behaviours in animals and mimic certain aspects of psychotic disorders in humans [20, 23-25]. Amphetamine, an indirectly acting sympathomimetic, causes increased dopamine release from presynaptic terminals [26], and hyperlocomotion induced by amphetamine is dependent upon intact subcortical dopamine activity in the nucleus accumbens [27]. In contrast, phencyclidine interferes with multiple neurotransmitter systems [28]. Phencyclidine acts as a non-competitive antagonist at the ion channel associated with the Nmethyl-D-aspartate (NMDA) glutamate receptor and also indirectly facilitates dopaminergic and serotonergic transmission [29]. Similar mechanisms are also activated in humans by phencyclidine [30]. Prepulse inhibition of the acoustic startle response is an operational measure of sensorimotor gating that is disrupted in patients with schizophrenia $[31,32]$ and in rats treated with drugs that facilitate dopaminergic activity [33-35]. Furthermore, prepulse inhibition is reduced in rats treated systemically with serotonin releasers, such as fenfluramine, direct 5 $\mathrm{HT}_{1 \mathrm{~A}}$ receptor agonists [36-38] and glutamate receptor antagonists, such as phencyclidine [39]. The prepulse inhibition-acoustic startle reflex model in rats offers a unique opportunity to asses attentional and information processing deficits in schizophrenia, as modulation of the startle responses is similar among mammalian species [40]. In animals, usually the whole body startle response is measured after exposure to acoustic or tactile stimuli, while in humans the eyeblink component of the startle response is measured [40].

There is a growing body of evidence that suggests that the hippocampus, amygdala and prefrontal cortex play an important role in the pathogenesis of schizophrenia. The activity of these brain regions may cause changes in subcortical dopaminergic activity and therefore lead to the inappropriate initiation of behavioural responses to external stimuli. We have previously reported that serotonergic projections into the hippocampus and amygdala are differentially involved in the regulation of psychotomimetic drug-induced locomotor hyperactivity and prepulse inhibition $[41,42]$. As serotonergic projections from both raphe nuclei innervate the prefrontal cortex, in addition to the hippocampus and amygdala, the aim of the present study was to determine whether serotonergic lesions of the prefrontal cortex caused behavioural changes similar to those produced by lesions of the hippocampus and/or amygdala.

In humans, dysfunction of the prefrontal cortical areas, with which the medial prefrontal cortex of the rat is comparable, is related to psychopathology of schizophrenia and other psychiatric disorders (for a review, see [43]). A wealth of evidence from studies in animals and humans indicates that the medial prefrontal cortex (mPFC) is a key component of the cortico-limbic-striatal circuits that generate pathological emotional behaviour $[44,45]$. The various subdivisions of the mPFC appear to serve separate and distinct functions. For example, ven- 
tral regions of the $\mathrm{mPFC}$ (the prelimbic and the infralimbic cortices) have been associated with diverse emotional and cognitive processes [43, 46, 47]. The ventral mPFC is also of interest, as it has been strongly implicated in the expression of behavioural and autonomic responses to emotionally relevant stimuli [48]. As dysfunction of the prefrontal cortex has been repeatedly implicated in the pathophysiology of schizophrenia [49-52], studies in the rat have focused on elucidating the role of this region in paradigms such as locomotor activity and prepulse inhibition. Dopaminergic lesions and intra-mPFC infusion of selective dopamine receptor antagonists have been reported to disrupt prepulse inhibition $[53,54]$, whereas the intra-mPFC infusion of amphetamine has been shown to decrease systemic amphetamine-induced increases in locomotor activity in the open field test [55]. However, none of these studies have addressed the importance of serotonergic innervation of the MPFC in neural circuitry involved in the regulation of motor behaviour and prepulse inhibition. Therefore, the present study investigated the effects of local lesions of serotonergic projections into the mPFC on psychotomimetic drug-induced locomotor hyperactivity and prepulse inhibition.

\section{MATERIALS AND METHODS}

\section{Experimental animals}

A total of 25 male Sprague-Dawley rats (Department of Pathology, University of Melbourne), weighing 250$300 \mathrm{~g}$ at the time of surgery, were used in this study. The animals were housed under standard conditions in groups of two or three with free access to food and water. They were maintained on a $12 \mathrm{~h}$ light/dark cycle (lights on at $0700 \mathrm{~h}$ ) at a constant temperature of $21^{\circ} \mathrm{C}$. One week prior to the surgical procedure, the animals were handled each day over a five-day period. The experimental protocol and surgical procedures were approved by the Animal Experimentation Ethics Committee of the University of Melbourne, Australia.

\section{Drugs and solutions}

D-amphetamine sulphate (Sigma Chemical Co., St. Louis, MO, USA) and phencyclidine $\mathrm{HCl}$ (PCP, Sigma) were dissolved in a $0.9 \%$ saline solution and injected subcutaneously (s.c.) into the nape of the neck. Desipramine $\mathrm{HCl}$ (Sigma) was dissolved in distilled water and injected intraperitoneally (i.p) $30 \mathrm{~min}$ prior to the neurotoxin microinjection. All doses are expressed as the weight of the salt and were administered in an injection volume of $1 \mathrm{ml} /$ $\mathrm{kg}$ body weight. The serotonergic neurotoxin, 5,7-dihydroxytryptamine (5,7-DHT) (Sigma), was dissolved in 0.1\% ascorbic acid (BDH Chemicals, Kilsyth, VIC, Australia) in saline to prevent oxidation of the neurotoxin. Carprofen (50 mg/ml, Heriot AgVet, Rowille, VIC, Australia) was diluted in $0.9 \%$ saline to a dose of $5 \mathrm{mg} / \mathrm{kg}$ and injected s.c. immediately after the surgical procedure.

\section{Surgical procedure}

The rats were pretreated with $20 \mathrm{mg} / \mathrm{kg}$ desipramine, 30 min prior to surgery, to prevent the destruction of noradrenergic neurons by 5,7-DHT [56]. The rats were subsequently anaesthetised with sodium pentobarbitone (60 mg/kg i.p., Rhone Merieux, QLD, Australia). The rats were mounted in a Kopf stereotaxic frame (David Kopf Instruments, Tujunga, CA, USA) with the incisor bar set at -3.3 $\mathrm{mm}$ [57]. The skull surface was exposed, and a small hole was drilled. A 25 gauge stainless-steel cannula, which was attached to a $10 \mu$ l glass syringe and connected via polyethylene tubing mounted in an infusion pump (UltraMicroPump, World Precision Instruments, Sarasota, FL, USA), was lowered into the mPFC. With bregma set to zero and the stereotaxic arm at $0^{\circ}$, the coordinates were as follows: mPFC lesions $(n=13$ for behavioural experiments, $n=2$ for histology): $3.2 \mathrm{~mm}$ anterior, $0.7 \mathrm{~mm}$ lateral and $4.5 \mathrm{~mm}$ ventral to bregma. A volume of $0.5 \mu \mathrm{l}$ of $5,7-\mathrm{DHT}(5 \mu \mathrm{g} / \mu \mathrm{l})$ was infused over a period of $2 \mathrm{~min}$ on each side. Sham-operated controls $(n=10)$ underwent the same surgical procedure and received an equal volume of vehicle solution. The injection volumes and rate of infusion were selected to minimise non-specific damage at the site of injection. Movement of the meniscus in the cannula was monitored to ensure successful infusion. After infusion, the cannula was left in place for a further 2 min to avoid backflow of the solution up the injection path. After lesioning, the skin was closed with silk-2 sutures (Cynamid, Baulkham Hills, NSW, Australia), and the animals were administered $5 \mathrm{mg} / \mathrm{kg}$ of carprofen, a non-steroidal, anti-inflammatory analgesic, to reduce post-operative inflammation and discomfort. The rats were placed on a heated pad until they recovered from the anaesthesia. After the surgery, the rats were allowed to recover for two weeks, during which they were handled regularly and health checks were made two to three times a week.

\section{Experimental design and apparatus}

Behavioural tests were performed starting two weeks after the surgery, and each session included random numbers of 5,7-DHT-lesioned rats and sham-operated rats. Locomotor activity was monitored using eight automated photocell cages ( $31 \times 43 \times 43 \mathrm{~cm}$, h x w x 1, ENV-520, MED Associates, St. Albans, VT, USA). The position of the rat at any time was detected with sixteen evenly spaced infrared sources and sensors on each of the four sides of the monitor. The addition of a photobeam array above the subject added a second plane of detection to the system to detect rearing and vertical counts. This infrared beam array thus defined an X, Y and Z coordinate map for the system. The sensors detected the presence or absence of the infrared beam at these coordinates. Every $50 \mathrm{msec}$, the software checked for the presence or absence of the infrared beam at each sensor, allowing for the very precise tracking of the movement of a subject. Several types of behavioural responses were recorded, including distance moved, ambulation, stereotypy and rearing. Ambulatory counts con- 
sisted of consecutive interruptions of at least four beams within a period of $500 \mathrm{~ms}$. Small, repetitive beam breaks within a virtual box of $4 \times 4$ beams around the rat were recorded as stereotypic counts. Recordings of photocell beam interruptions by the rat were taken every $5 \mathrm{~min}$ and stored by the computer software. Three locomotor activity tests were done after treatment with saline, 0.5 $\mathrm{mg} / \mathrm{kg}$ of amphetamine or $2.5 \mathrm{mg} / \mathrm{kg}$ of phencyclidine administered in a random order. These locomotor activity tests were done with three to four day intervals to prevent habituation due to repeated testing and to allow for clearance of the drugs. Prior to any drug manipulation, the rats were placed in the locomotor photocell cages for $30 \mathrm{~min}$ to establish baseline locomotor activity and allow for habituation to the test environment. After $30 \mathrm{~min}$ of spontaneous baseline activity, the rats were injected and locomotor activity was recorded over a further $90 \mathrm{~min}$, generating a total session time of two hours. For the purpose of this paper, locomotor activity data were expressed as cumulative data from $30 \mathrm{~min}$ periods and presented as a time course of distance moved during the $30 \mathrm{~min}$ before injection and $90 \mathrm{~min}$ after injection.

After locomotor activity experiments, rats were tested for prepulse inhibition. This was done using six automated startle chambers (SR-LAB, San Diego Instruments, San Diego, CA, USA) consisting of clear Plexiglas cylinders, 9 $\mathrm{cm}$ in diameter, resting on a platform inside a ventilated, sound-attenuated and illuminated chamber. A speaker mounted $24 \mathrm{~cm}$ above the cylinder produced both continuous background noise at $70 \mathrm{~dB}$ and the various acoustic stimuli. Whole-body startle responses of the animal in response to acoustic stimuli caused vibrations of the Plexiglas cylinder, which were then converted into quantitative responses by a piezoelectric accelerometer unit attached beneath the platform. The percent prepulse inhibition was calculated as $100 \mathrm{x}$ \{[pulse-alone trials - (prepulse + pulse trials )] /(pulse-alone trials)\} [31]. At least one day before the prepulse inhibition testing, rats underwent a pretest session where they were exposed to the testing cylinders and the testing protocol for the first time. This session was conducted to allow rats to habituate to the testing environment. Each rat was placed into the chamber for a $5 \mathrm{~min}$ acclimation period with a $70 \mathrm{~dB}$ background noise level that continued throughout the session. A single prepulse inhibition session lasted for about $45 \mathrm{~min}$ and consisted of high- and low-intensity stimulus combinations with a continuous background noise of $70 \mathrm{~dB}$. The session started and ended with a block of ten pulse-alone trials of 115 $\mathrm{dB}$. These blocks, together with twenty pseudo-randomly presented pulse-alone trials during the prepulse inhibition protocol, were used to calculate the basal startle reactivity and startle habituation. Prepulses were presented for $20 \mathrm{~ms}$ and differed in intensity. Prepulse inhibition was assessed by the random presentation of $115 \mathrm{~dB}$ pulses, ten each of prepulse-2, $-4,-8,12$ and -16 and ten 'no-stimulus' trials. For example, prepulse- 8 (PP8) is a 20-ms prepulse of $8 \mathrm{~dB}$ above the background noise, i.e., $78 \mathrm{~dB}$, followed $100 \mathrm{~ms}$ later by a 40-ms $115 \mathrm{~dB}$ pulse [58]. The interval between trials varied $(10-37 \mathrm{~s})$ to prevent conditioning of the responses. A microcomputer and an interface assembly that controlled the delivery of acoustic stimuli digitised and recorded the readings.

Tissue preparation for histology and high pressure liquid chromatography (HPLC)

At the end of the experiments, rats were killed by decapitation and the brains were removed from the skull. The brains were placed on a cold plate. First, the frontal cortex was dissected bilaterally [59], and then the mPFC was dissected out. For the histological assessment of the location of the injection sites, $20-\mu \mathrm{m}$-thick sections of the medial prefrontal cortex of two mPFC-lesioned rats were cut on a cryostat and mounted onto gelatin-coated glass slides. The sections were then stained with cresyl violet (ProSciTech, Thuringowa, QLD, Australia) and examined microscopically to verify the location of the tips of the infusion cannulas.

The HPLC measurements of the tissue serotonin (5-HT) concentration were carried out in 23 animals. The dissected structures were weighed and stored in Eppendorf tubes at $-80^{\circ} \mathrm{C}$ until the biochemical assays were performed. The tissue samples were homogenised in $500 \mu \mathrm{l}$ of $0.1 \mathrm{M}$ perchloric acid by ultrasonication and centrifuged at 15,500 g for 5 min. A $50 \mu \mathrm{l}$ aliquot of the supernatant was injected into a high pressure liquid chromatography (HPLC) system to determine the content of 5 -HT (ng/mg tissue of wet weight). The HPLC system consisted of a Waters Model 510 Solvent delivery system, a Waters U6K injector, an Alphabond C18 125A 10 U 150* 3.9 mm column and a Column \& SpectraPhysics 970 D-A1 fluorescence spectrometer. The output signal from the fluorescence detector was analysed with the chromatography software package, 810 Baseline, version 3.31. The mobile phase used consisted of $9.8 \mathrm{~g} / \mathrm{K} \mathrm{KH}_{2} \mathrm{PO}_{4}, 1.0$ $\mathrm{g} / \mathrm{l} \mathrm{Na}{ }_{2} \mathrm{EDTA}, 5 \%$ acetonitrile and $1 \mathrm{ml} / \mathrm{l}$ triethylamine. The $\mathrm{pH}$ of the mobile phase solution was adjusted to 3.0 with 1 $\mathrm{M} \mathrm{HCl}$. Subsequently, the solution was filtered and degassed and delivered to the HPLC at a flow rate of $1 \mathrm{ml} / \mathrm{min}$. Prior to sample testing, the following standards for 5 - $\mathrm{HT}$ were run through the system: $12.5 \mathrm{ng} / \mathrm{ml}, 25 \mathrm{ng} / \mathrm{ml}, 50 \mathrm{ng} / \mathrm{ml}, 100 \mathrm{ng} /$ $\mathrm{ml}$ and $200 \mathrm{ng} / \mathrm{ml}$. Calibration curves were constructed, and the level of 5-HT in tissue samples was calculated relative to these standards. Each run lasted $8 \mathrm{~min}$ and the retention time for serotonin was $2.6 \mathrm{~min}$.

\section{Statistical analysis}

Data were expressed as the mean \pm the standard error of the mean (SEM). All of the statistical analyses were performed using the statistical software package SYSTAT 9.0 (SPSS Inc., Chicago, IL, USA). All of the data were analysed using an analysis of variance (ANOVA) with repeated measures where appropriate. In the locomotor activity experiments, data were summed in 30-min blocks, and these blocks were used to assess the main effects of the lesion type (group), the treatment with amphetamine or phency- 
clidine (time) and the interactions between these factors. In this analysis, the time effect was a repeated-measures factor. The baseline and the drug-induced locomotor activity were part of the data set analysed. In the prepulse inhibition experiments, the factors were group and habituation (four blocks of ten startle responses) or group and prepulse (five different prepulse intensities), where habituation and prepulse were repeated-measures factors. After calculating ANOVAs for all of the surgery groups, subsequent pairwise ANOVAs were performed where needed. A 'p-value' of $\mathrm{p}<0.05$ was considered to be statistically significant. For HPLC measurements, a one-way ANOVA was used, followed by the Bonferroni-corrected t-test comparison.

\section{RE SULTS}

\section{Histology: injection sites}

Inspection of cresyl violet-stained brain sections from two animals revealed that the tip of the infusion cannula was situated within the boundaries of the mPFC, as delineated by the Paxinos and Watson rat brain atlas [57].

\section{HPLC: 5-HT depletion}

The behavioural data of four mPFC-lesioned rats with partial depletions of 5 -HT ( $<50 \%)$, as measured by HPLC, were excluded from the study. The final group size for the analysis was $n=10$ for the sham-operated group and $n=9$ for the $\mathrm{mPFC}$-lesioned group. In the mPFC-lesioned rats, the local injection of 5,7 DHT caused a marked reduction of the 5 -HT concentration in the mPFC. After the microinjection of 5,7-DHT into the $\mathrm{MPFC}$, the concentration of 5 -HT was reduced by $60 \%$ (Figure 1). An ANOVA revealed a significant reduction of the 5 -HT concentration in the mPFC-lesioned rats compared to the controls $\left(\mathrm{F}_{1,17}=92.3, \mathrm{p}<0.001\right)$.

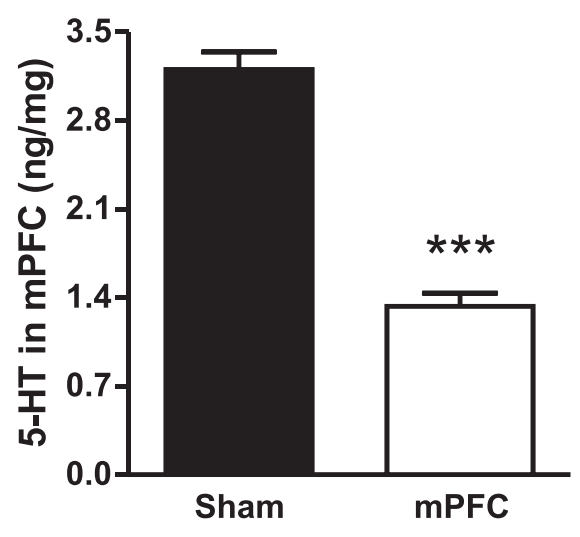

Figure 1

5-HT content in the MPFC after sham surgery or 5,7 DHT microinjection into the $\mathrm{mPFC}$. The data are expressed as the average 5-HT concentration (ng/mg of tissue wet weight) \pm SEM. ${ }^{* * * *} \mathrm{p}<0.001$ for the difference in the 5-HT concentration between the mPFC-lesioned rats and the shamoperated control rats as indicated by ANOVA.
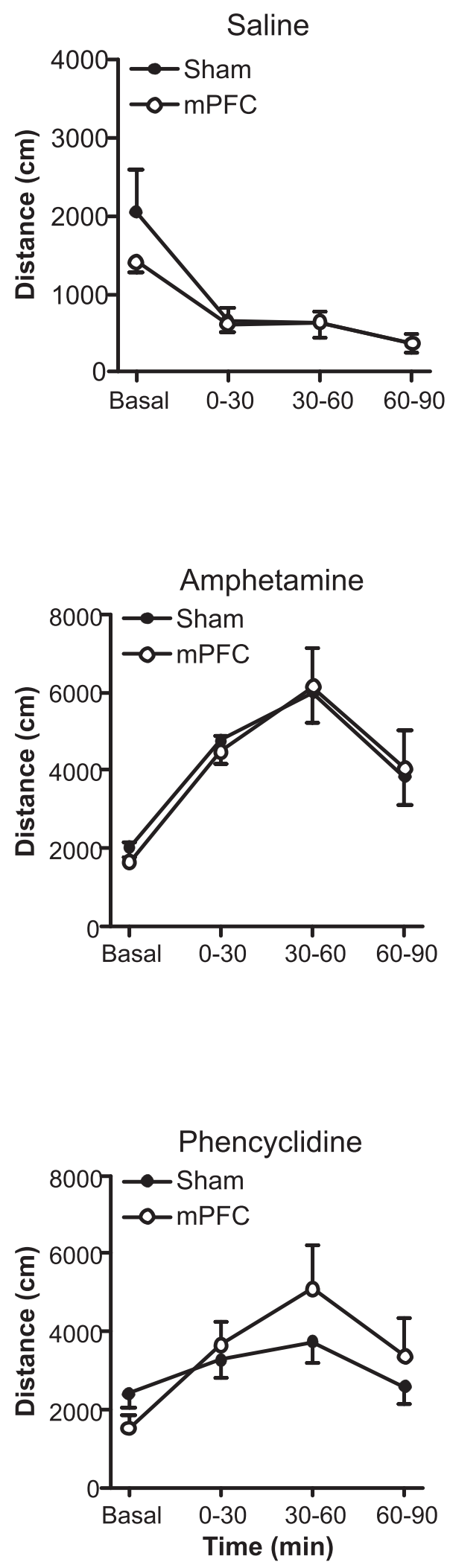

Figure 2

Time course of the effects of a subcutaneous injection of saline, $0.5 \mathrm{mg} /$ $\mathrm{kg}$ of amphetamine or $2.5 \mathrm{mg} / \mathrm{kg}$ of phencyclidine on locomotor activity in sham-operated rats and rats with 5,7 DHT-induced mPFC lesions. Locomotor hyperactivity is expressed as the distance moved $(\mathrm{cm}) \pm$ SEM for sham-operated $(n=10, \bullet)$ and mPFC-lesioned rats $(n=9,0)$. There were no significant differences between the groups. 

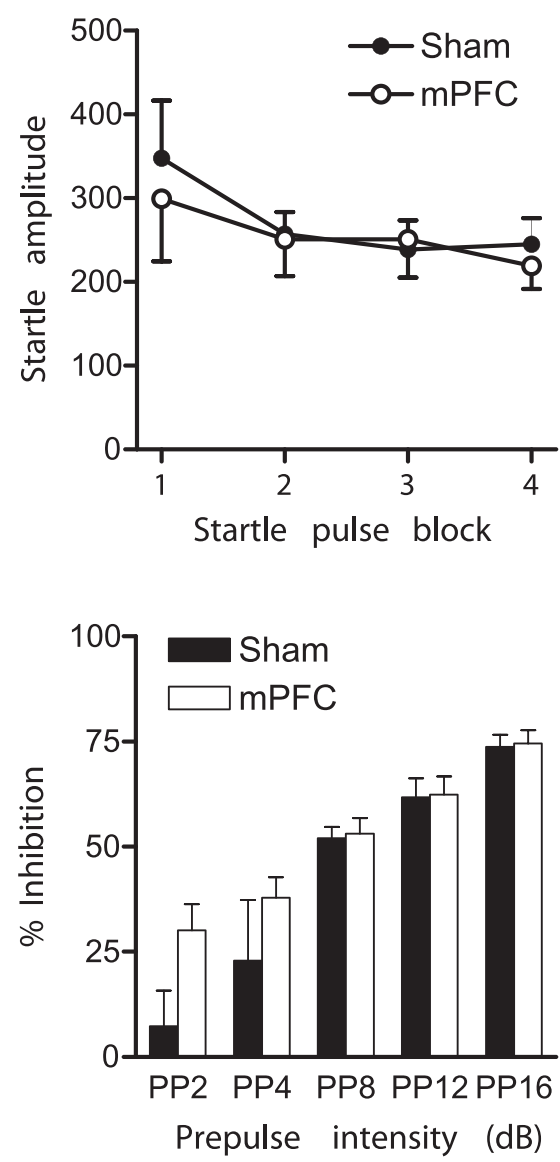

Figure 3

Effect of sham surgery $(n=10)$ or 5,7-DHT lesions of the mPFC $(n=9)$ on startle amplitude, startle habituation and prepulse inhibition. The top panel illustrates the basal startle reactivity and the startle habituation. The data are expressed as mean startle amplitudes \pm SEM for each of the four blocks of ten $115 \mathrm{~dB}$ pulses. The bottom panel illustrates the prepulse inhibition of the acoustic startle response. The prepulse inhibition is expressed as the \% inhibition \pm SEM at different prepulse intensities. There were no significant differences between the groups as indicated by ANOVA.

The effects of the microinjection of 5,7-DHT on amphetamine- and phencyclidine-induced locomotor hyperactivity

The locomotor hyperactivity caused by treatment with amphetamine or phencyclidine was not significantly different between sham-operated rats and $\mathrm{mP}-$ FC-lesioned rats (Figure 2). After treatment with either amphetamine or phencyclidine, there was an expected main effect of time $\left(\mathrm{F}_{2,34}=10.4, \mathrm{p}<0.001\right.$ and $\mathrm{F}_{2,34}=5.4$, $\mathrm{p}=0.01$, respectively), reflecting the increases in activity caused by these treatments. The lack of a main group effect or a time $\mathrm{x}$ group interaction suggested that the time course of the effects of either amphetamine or phencyclidine was not altered after mPFC-lesions. Lesioned animals tended to show increased phencyclidine responses (Figure 2, bottom panel); however, this was seen in only two out of nine rats. The analysis of the 5-HT concentrations in these two rats did not reveal any differences in the level of 5-HT depletion in comparison with the other rats. After a saline injection, the locomotor activity levels were very low, and there was no significant difference between the lesioned group and the sham-operated group (Figure 2).

The effects of the microinjection of 5,7-DHT on the startle response, habituation and prepulse inhibition

The startle amplitude in the pulse-alone trials and the habituation of the rats were not different between the $\mathrm{mP}$ FC-lesioned rats compared to the sham-operated controls (Figure 3). An ANOVA revealed that there was no significant main effect of group or of the habituation $x$ group interaction. Figure 4 appeared to suggest that the mPFC-lesioned rats showed an increase in prepulse inhibition at PP2 and PP4 compared to the sham-operated controls; however, an ANOVA indicated that there was no significant main effect of group or of the prepulse $\mathrm{x}$ group interaction.

\section{DISCUSSION}

The behavioural assessment of rats with serotonergic lesions of the MPFC, using the locomotor hyperactivity and prepulse inhibition paradigms, revealed that there were no differences between the lesioned and control groups. The present findings suggest that normal regulation of locomotor activity and prepulse inhibition is independent of serotonin release from terminals in the mPFC.

\section{Serotonin in the mPFC}

\section{and psychotomimetic drug action}

As previously reported [41], it is likely that serotonin release from terminals in the dorsal hippocampus has an inhibitory effect on glutamatergic projections to the core of the nucleus accumbens. Disruption of this inhibition may lead to increased glutamatergic transmission in the nucleus accumbens and enhancement of phencyclidine-induced hyperlocomotion. In addition, enhancement of glutamatergic transmission has been shown to have an opposite effect on amphetamine-induced hyperlocomotion [41].

It has been shown that phencyclidine enhances glutamate release in the prefrontal cortex to compensate for the blockade of NMDA receptors, which leads to the overstimulation of postsynaptic non-NMDA glutamate receptors $[60,61]$. Additionally, the acute administration of phencyclidine promotes dopamine release in the prefrontal cortex [62]. It has been reported that group II metabotropic glutamate receptor agonists and nonNMDA receptor antagonists diminish phencyclidineinduced hyperlocomotion by preventing the responses of pyramidal cells of the rat mPFC [60,61]. We suggest that serotonin depletion in the mPFC does not influence phencyclidine-induced dopamine or glutamate release in this brain region. Furthermore, our results suggest that glutamatergic transmission in the nucleus accumbens is not altered after the manipulation of serotonin release in the mPFC. We postulate that the effect of en- 
hanced glutamatergic transmission on the amphetamine response depends on the balance of NMDA and nonNMDA receptor activation interacting with dopamine $\mathrm{D}_{1}$ and $\mathrm{D}_{2}$ receptors. Both NMDA and non-NMDA receptors in the nucleus accumbens are located at the presynaptic level on glutamatergic and dopaminergic terminals arising from the cortex, the hippocampus and the midbrain, respectively (for a review see [63]). Our results suggest that serotonin depletion in the mPFC does not influence either dopaminergic or glutamatergic transmission within the nucleus accumbens.

\section{Serotonin in the MPFC and prepulse inhibition}

Prepulse inhibition is thought to be mediated by a prefrontocortico-limbic-striato-pallidal circuit in which the mPFC plays an important role [64]. Manipulations that decrease dopamine levels in the $\mathrm{mPFC}$ disrupt prepulse inhibition $[53,54]$, presumably by disinhibition of the descending glutamatergic projections [64]. The mPFC sends direct glutamatergic projections to the nucleus accumbens and the ventral tegmental area (VTA) [65], from which dopaminergic projections ascend to the nucleus accumbens. Stimulation of the mPFC increases dopamine release in the nucleus accumbens, probably via the VTA $[66,67]$. It is therefore possible that disinhibition of the mPFC glutamatergic output to the VTA increases dopamine release in the nucleus accumbens and thereby reduces prepulse inhibition [68]. Our results suggest that serotonin depletion in the $\mathrm{mPFC}$ does not alter $\mathrm{mPFC}$ output neurons to either the VTA or the nucleus accumbens, thus having no effect on sensorimotor gating.

In conclusion, serotonin depletion in the mPFC does not lead to the dysregulation of subcortical dopaminergic activity and does not cause aberrant responses to environmental stimuli. It is therefore clear that the behavioural effects of raphe lesions described in our initial studies [69, $70]$ are not mediated by serotonin depletion in the mPFC.

\section{REFERENCES}

1. Awad, A.G. and L.N. Voruganti, Impact of atypical antipsychotics on quality of life in patients with schizophrenia. CNS Drugs, 2004. 18(13): p. 877-893.

2. Harrison, P.J., The neuropathology of schizophrenia. Brain, 1999. 122: p. 593-624.

3. Carlsson, A. and M. Lindqvist, Effect of chlorpromazine or haloperidol on formation of 3-methoxytyramine and normetanephrine in mouse brain. Acta Pharmacol Toxicol, 1963. 20: p. 140-144.

4. Josselyn, S.A., R. Miller, and R.J. Beninger, Behavioral effects of clozapine and dopamine receptor subtypes. Neurosci Biobehav Rev, 1997. 21(5): p. 531-558.

5. Peroutka, S.J. and S.H. Synder, Relationship of neuroleptic drug effects at brain dopamine, serotonin, alphaadrenergic, and histamine receptors to clinical potency. Am J Psychiatry, 1980. 137(12): p. 1518-1522.
6. Bymaster, F., et al., Olanzapine: a basic science update. Br J Psychiatry Suppl, 1999(37): p. 36-40.

7. Carlsson, A., N. Waters, and M.L. Carlsson, Neurotransmitter interactions in schizophrenia--therapeutic implications. Biol Psychiatry, 1999. 46(10): p. 1388-1395.

8. Weiner, D.M., et al., 5-hydroxytryptamine2A receptor inverse agonists as antipsychotics. J Pharmacol Exp Ther, 2001. 299(1): p. 268-276.

9. Costall, B. and R.J. Naylor, Serotonin and psychiatric disorders. A key to new therapeutic approaches. Arzneimittelforschung, 1992. 42(2A): p. 246-249.

10. Meston, C.M. and B.B. Gorzalka, Psychoactive drugs and human sexual behavior: the role of serotonergic activity. J Psychoactive Drugs, 1992. 24(1): p. 1-40.

11. Schlundt, D.G., et al., A sequential behavioral analysis of craving sweets in obese women. Addict Behav, 1993. 18(1): p. 67-80.

12. Azmitia, E.C. and P.M. Whitaker-Azmitia, Anatomy, cell biology, and plasticity of the serotonergic system. Neuropsychopharmacological implications for the actions of psychotropic drugs, in Psychopharmacology: the fourth generation of progress, F.E. Bloom and D.J. Kupfer, Editors. 1995, Raven Press: New York. p. 443-449.

13. Hornung, J.P., The human raphe nuclei and the serotonergic system. J Chem Neuroanat, 2003. 26(4): p. 331-343.

14. Adell, A. and R.D. Myers, Selective destruction of midbrain raphe nuclei by 5,7-DHT: is brain 5-HT involved in alcohol drinking in Sprague-Dawley rats? Brain Res, 1995. 693(1-2): p. 70-79.

15. McQuade, R. and T. Sharp, Functional mapping of dorsal and median raphe 5-hydroxytryptamine pathways in forebrain of the rat using microdialysis. J Neurochem, 1997. 69(2): p. 791-796.

16. Mokler, D.J., et al., Serotonin neuronal release from dorsal hippocampus following electrical stimulation of the dorsal and median raphe nuclei in conscious rats. Hippocampus, 1998. 8(3): p. 262-273.

17. Thomas, H., et al., Lesion of the median raphe nucleus: a combined behavioral and microdialysis study in rats. Pharmacol Biochem Behav, 2000. 65(1): p. 15-21.

18. Abi-Dargham, A., et al., The role of serotonin in the pathophysiology and treatment of schizophrenia. J Neuropsych Clin Neurosci, 1997. 9(1): p. 1-17.

19. Kapur, S. and G. Remington, Serotonin-dopamine interaction and its relevance to schizophrenia. Am J Psychiatry, 1996. 153(4): p. 466-476.

20. Geyer, M.A. and A. Markou, Animal models of psychiatric disorders, in Psychopharmacology: the fourth generation of progress, F. Bloom and D. Kupfer, Editors. 1995, Raven Press: New York. p. 787-798.

21. Koch, M., Can animal models help to understand human diseases? Commentary on Swerdlow et al., 'Animal models of deficient sensorimotor gating: what we know, what we think we know, and what we hope to know soon. Behav Pharmacol, 2000. 11(3-4): p. 205-207.

22. Matthysse, S., Animal models in psychiatric research. Prog Brain Res, 1986. 65: p. 259-270. 
23. Ellenbroek, B.A., Pre-attentive processing and schizophrenia: animal studies. Psychopharmacology (Berl), 2004. 174(1): p. 65-74.

24. Ellenbroek, B.A. and A.R. Cools, Animal models with construct validity for schizophrenia. Behav Pharmacol, 1990. 1(6): p. 469-490.

25. Ellenbroek, B.A. and A.R. Cools, Animal models for the negative symptoms of schizophrenia. Behav Pharmacol, 2000. 11(3-4): p. 223-233.

26. Seiden, L.S., K.E. Sabol, and G.A. Ricaurte, Amphetamine: effects on catecholamine systems and behavior. Annu Rev Pharmacol Toxicol, 1993. 33: p. 639-677.

27. Kelly, P.H., P.W. Seviour, and S.D. Iversen, Amphetamine and apomorphine responses in the rat following 6-OHDA lesions of the nucleus accumbens septi and corpus striatum. Brain Res, 1975. 94(3): p. 507-522.

28. Contreras, P.C., et al., Phencyclidine. Physiological actions, interactions with excitatory amino acids and endogenous ligands. Mol Neurobiol, 1987. 1(3): p. 191-211.

29. Javitt, D.C. and S.R. Zukin, Recent advances in the phencyclidine model of schizophrenia. Am J Psychiatry, 1991. 148(10): p. 1301-1308.

30. Pradhan, S.N., Phencyclidine (PCP): some human studies. Neurosci Biobehav Rev, 1984. 8(4): p. 493-501.

31. Geyer, M.A., et al., Startle response models of sensorimotor gating and habituation deficits in schizophrenia. Brain Res Bull, 1990. 25(3): p. 485-498.

32. Swerdlow, N.R., et al., Seroquel, clozapine and chlorpromazine restore sensorimotor gating in ketamine-treated rats. Psychopharmacology (Berl), 1998. 140(1): p. 75-80.

33. Mansbach, R.S., M.A. Geyer, and D.L. Braff, Dopaminergic stimulation disrupts sensorimotor gating in the rat. Psychopharmacology (Berl), 1988. 94(4): p. 507-514.

34. Swerdlow, N.R., D.L. Braff, and M.A. Geyer, GABAergic projection from nucleus accumbens to ventral pallidum mediates dopamine-induced sensorimotor gating deficits of acoustic startle in rats. Brain Res, 1990. 532(1-2): p. 146-150.

35. Wan, F.J., M.A. Geyer, and N.R. Swerdlow, Presynaptic dopamine-glutamate interactions in the nucleus accumbens regulate sensorimotor gating. Psychopharmacology (Berl), 1995. 120(4): p. 433-441.

36. Mansbach, R.S., D.L. Braff, and M.A. Geyer, Prepulse inhibition of the acoustic startle response is disrupted by N-ethyl-3,4-methylenedioxyamphetamine (MDEA) in the rat. Eur J Pharmacol, 1989. 167(1): p. 49-55.

37. Rigdon, G.C. and J.K. Weatherspoon, 5-Hydroxytryptamine 1a receptor agonists block prepulse inhibition of acoustic startle reflex. J Pharmacol Exp Ther, 1992. 263(2): p. 486-493.

38. Sipes, T.A. and M.A. Geyer, Multiple serotonin receptor subtypes modulate prepulse inhibition of the startle response in rats. Neuropharmacology, 1994. 33(3-4): p. 441-448.

39. Mansbach, R.S. and M.A. Geyer, Effects of phencyclidine and phencyclidine biologs on sensorimotor gating in the rat. Neuropsychopharmacology, 1989. 2(4): p. 299-308.
40. Braff, D. and M. Geyer, Sensorimotor gating and the neurobiology of schizophrenia: human and animal model studies, in Schizophrenia: Scientific Progress, S. Schulz and C. Tamminga, Editors. 1989, Oxford University Press: Oxford. p. 124-137.

41. Kusljic, S. and M. van den Buuse, Functional dissociation between serotonergic pathways in dorsal and ventral hippocampus in psychotomimetic drug-induced locomotor hyperactivity and prepulse inhibition in rats. Eur J Neurosci, 2004. 20(12): p. 3424-3432.

42. Kusljic, S. and M. van den Buuse, Differential involvement of 5 -HT projections within the amygdala in prepulse inhibition but not in psychotomimetic druginduced hyperlocomotion. Behav Brain Res, 2006. 168(1): p. 74-82.

43. Heidbreder, C.A. and H.J. Groenewegen, The medial prefrontal cortex in the rat: evidence for a dorso-ventral distinction based upon functional and anatomical characteristics. Neurosci Biobehav Rev, 2003. 27(6): p. 555-579.

44. Drevets, W.C., et al., Subgenual prefrontal cortex abnormalities in mood disorders. Nature, 1997. 386(6627): p. 824-827.

45. Mayberg, H.S., et al., Reciprocal limbic-cortical function and negative mood: converging PET findings in depression and normal sadness. Am J Psychiatry, 1999. 156(5): p. 675-682.

46. Kolb, B., Functions of the frontal cortex of the rat: a comparative review. Brain Res, 1984. 320(1): p. 65-98.

47. Vertes, R.P., Differential projections of the infralimbic and prelimbic cortex in the rat. Synapse, 2004. 51(1): p. 32-58.

48. Hajos, M., et al., In vivo inhibition of neuronal activity in the rat ventromedial prefrontal cortex by midbrainraphe nuclei: role of 5-HT1A receptors. Neuropharmacology, 2003. 45(1): p. 72-81.

49. Grace, A.A., Phasic versus tonic dopamine release and the modulation of dopamine system responsivity: a hypothesis for the etiology of schizophrenia. Neuroscience, 1991. 41(1): p. 1-24.

50. Laruelle, M., et al., Selective abnormalities of prefrontal serotonergic receptors in schizophrenia. A postmortem study. Arch Gen Psychiatry, 1993. 50(10): p. 810-818.

51. Weinberger, D.R., K.F. Berman, and R.F. Zec, Physiologic dysfunction of dorsolateral prefrontal cortex in schizophrenia. I. Regional cerebral blood flow evidence. Arch Gen Psychiatry, 1986. 43(2): p. 114-124.

52. Weinberger, D.R. and B.K. Lipska, Cortical maldevelopment, anti-psychotic drugs, and schizophrenia: a search for common ground. Schizophrenia Res, 1995. 16(2): p. 87-110.

53. Ellenbroek, B.A., S. Budde, and A.R. Cools, Prepulse inhibition and latent inhibition: the role of dopamine in the medial prefrontal cortex. Neuroscience, 1996. 75(2): p. 535-542.

54. Koch, M. and M. Bubser, Deficient sensorimotor gating after 6-hydroxydopamine lesion of the rat medial prefrontal cortex is reversed by haloperidol. Eur J Neurosci, 1994. 6(12): p. 1837-1845. 
55. Lacroix, L., et al., Effects of local infusions of dopaminergic drugs into the medial prefrontal cortex of rats on latent inhibition, prepulse inhibition and amphetamine induced activity. Behav Brain Res, 2000. 107(1-2): p. 111-121.

56. Jonsson, G., Chemical neurotoxins as denervation tools in neurobiology. Ann. Rev. Neurosci., 1980. 3: p. 169-187.

57. Paxinos, G. and C. Watson, The rat brain in stereotaxic co-ordinates, 5th edition. 5th ed. 2005, New York: Elsevier Academic press.

58. Van den Buuse, M., Deficient prepulse inhibition of acoustic startle in Hooded-Wistar rats compared with Sprague-Dawley rats. Clin Exp Pharmacol Physiol, 2003. 30: p. 254-261.

59. Gispen, W.H., P. Schotman, and E.R. De Kloet, Brain RNA and hypophysectomy: a topographical study. Neuroendocrinology, 1972. 9: p. 285-296.

60. Moghaddam, B., et al., Activation of glutamatergic neurotransmission by ketamine: a novel step in the pathway from NMDA receptor blockade to dopaminergic and cognitive disruptions associated with the prefrontal cortex. J Neurosci, 1997. 17(8): p. 2921-2927.

61. Moghaddam, B. and B.W. Adams, Reversal of phencyclidine effects by a group II metabotropic glutamate receptor agonist in rats. Science, 1998. 281(5381): p. 1349-1352.

62. Jentsch, J.D., et al., Alpha-noradrenergic receptor modulation of the phencyclidine- and delta9-tetrahydrocannabinol-induced increases in dopamine utilization in rat prefrontal cortex. Synapse, 1998. 28(1): p. 21-26.

63. Tarazi, F.I. and R.J. Baldessarini, Regional localization of dopamine and ionotropic glutamate receptor sub- types in striatolimbic brain regions. J Neurosci Res, 1999. 55(4): p. 401-410.

64. Swerdlow, N.R., M.A. Geyer, and D.L. Braff, Neural circuit regulation of prepulse inhibition of startle in the rat: current knowledge and future challenges. Psychopharmacology (Berl), 2001. 156(2-3): p. 194-215.

65. Sesack, S.R. and V.M. Pickel, Prefrontal cortical efferents in the rat synapse on unlabeled neuronal targets of catecholamine terminals in the nucleus accumbens septi and on dopamine neurons in the ventral tegmental area. J Comp Neurol, 1992. 320(2): p. 145-160.

66. Karreman, M. and B. Moghaddam, The prefrontal cortex regulates the basal release of dopamine in the limbic striatum: an effect mediated by ventral tegmental area. J Neurochem, 1996. 66(2): p. 589-598.

67. Taber, M.T., S. Das, and H.C. Fibiger, Cortical regulation of subcortical dopamine release: mediation via the ventral tegmental area. J Neurochem, 1995. 65(3): p. 1407-1410.

68. Koch, M., The neurobiology of startle. Prog Neurobiol, 1999. 59(2): p. 107-128.

69. Kusljic, S., et al., Brain serotonin depletion by lesions of the median raphe nucleus enhances the psychotomimetic action of phencyclidine, but not dizocilpine (MK801), in rats. Brain Res, 2005. 1049(2): p. 217-226.

70. Kusljic, S., D.L. Copolov, and M. van den Buuse, Differential role of serotonergic projections arising from the dorsal and median raphe nuclei in locomotor hyperactivity and prepulse inhibition. Neuropsychopharmacology, 2003. 28(12): p. 2138-2147. 


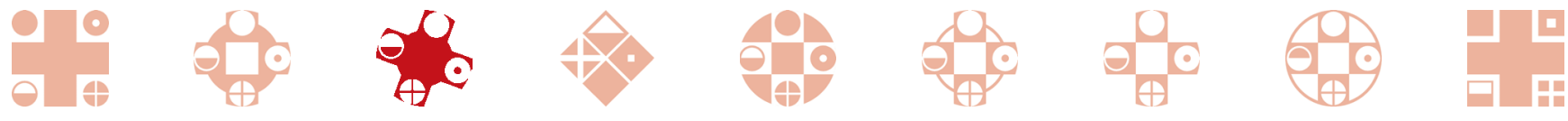

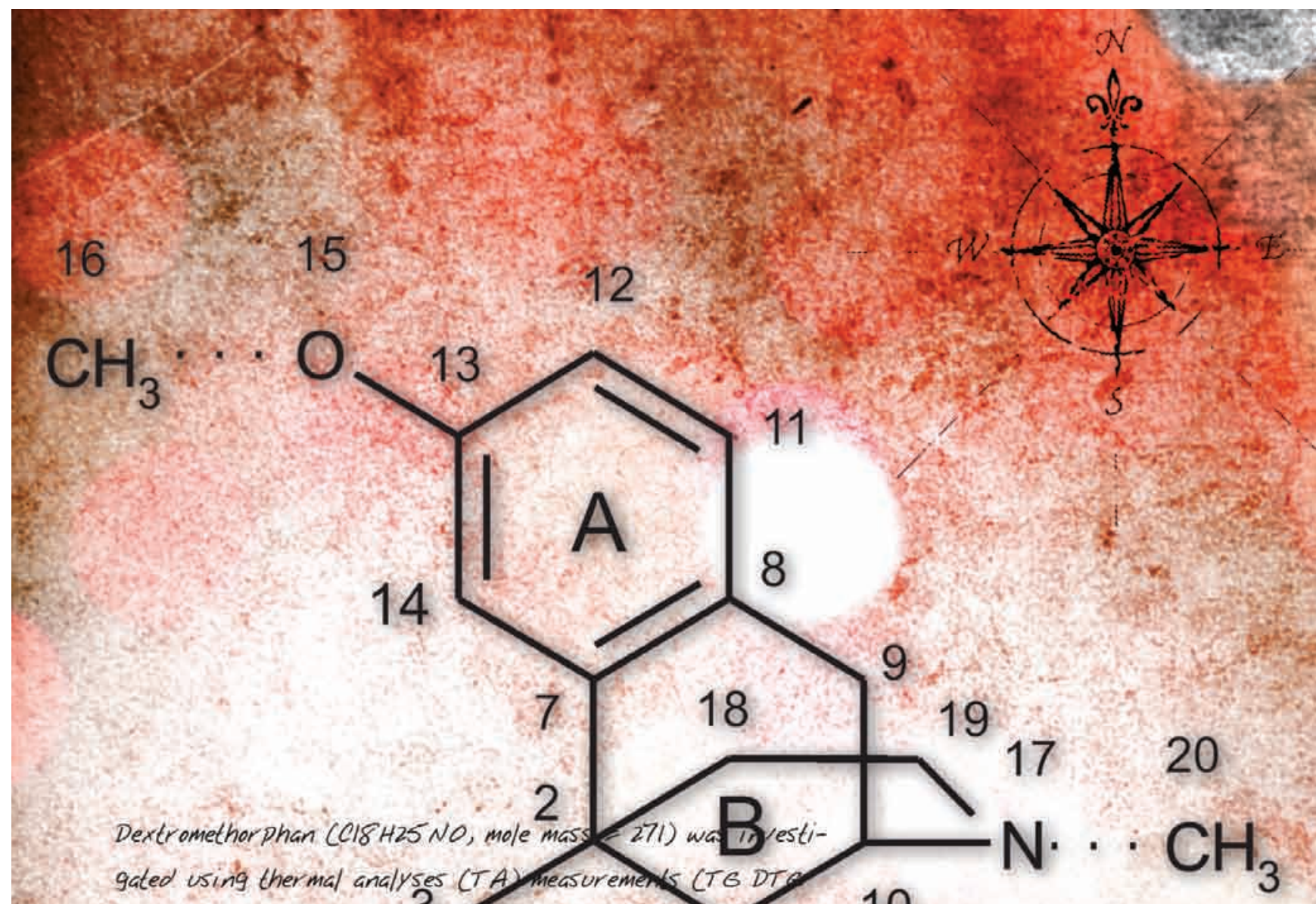
and-DSC) compared with 3 , lass spectral (MS) ele bron 10 impact fragmentation at 70 of of electronenergy sqmi-empirical mo calculations using th. PM-3 pr cecure were performed with dextromethorph $(D M P)$ as a neutral joleagle and the corresponding positive Narged ion. Th se included molecular geometry (bond length), bond wer, bond strain, charge, distribution on different atoms, heat of formation, and ionisation energy. The mass spectraf 5 ragmentation pathways and thermal analyses decomposition were proposed and compared with each other to select the most suitable scheme in electron ionisation (EI) mass spectral fragmentation, the initial rupture is due to C3H7N (bridge) loss followed by CQHIllo in TA: the primary loss is due to loss of CBHTN Bridge + HBr (affer 420 loss of crystallisation) TA revealed a high response of the drug to the temperature variation with very fast ate it decomposed in several sequential steps in temperaure range from $100 \rrbracket d$ to $6000 \mathrm{C}$. The initial thermal decom-

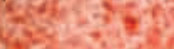

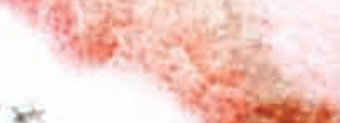

